\title{
El descubrimiento del Yacimiento de la Magdalena. Protagonismo de los métodos geofísicos en la exploración de yacimientos tipo sulfuros masivos vulcanogénicos (vms) profundos en la faja pirítica ibérica.
}

\author{
(1) Minas de Aguas Teñidas, S.A.U. (MATSA) \\ juan.pons@matsamining.com \\ juan.videira@matsamining.com \\ (2) International Geophysical Technology, S.L. (IGT) \\ agranda@igt-geofisica.com \\ tgranda@igt-geofisica.com
}

Ángel Granda Sanz ${ }^{(2)}$, Teresa Granda París ${ }^{(2)}$, Juan Manuel Pons ${ }^{(1)}$ y Juan Carlos Videira(1)

\begin{abstract}
RESUMEN
El yacimiento de sulfuros polimetálicos de La Magdalena, localizado a $8 \mathrm{~km}$ al Este de la Mina de Aguas Teñidas en la provincia de Huelva en un contexto geológico semejante, constituye el mayor descubrimiento realizado en la Faja Pirítica española en las últimas décadas. Fue descubierto por la empresa Minas de Aguas Teñidas S.A.U. (MATSA) en mayo de 2013, al reconocer una anomalía geofísica definida por un estudio con el método electromagnético VTEM heliportado (Versatile Transient EM), mediante un sondeo que intersectó sulfuros metálicos masivos entre 225 y 248 metros de profundidad. En paralelo con la campaña posterior de sondeos la compañía International Geophysical Technology, S.L. (IGT) realizó otros estudios geofísicos mediante diversos métodos (Mise-à-la-Masse, Microgravimetría, Tomografía Eléctrica, Electromagnético en Dominio de Tiempos (TEM), Magnetometría), que contribuyeron a la mejor programación de la campaña de sondeos al definir la continuidad de la mineralización que se llamó Masa 1. La contribución más interesante de los métodos geofísicos en este proyecto fue el descubrimiento de una segunda masa de sulfuros metálicos más profunda y de mayor tamaño, denominada Masa 2, situada entre $350 \mathrm{~m}$ y $1100 \mathrm{~m}$ de profundidad, que había quedado fuera del alcance del estudio VTEM. Se manifestó como una anomalía off-hole en los registros TEM obtenidos en un sondeo estéril (MA-21) perforado inicialmente hasta $320 \mathrm{~m}$ de profundidad. La anomalía TEM registrada en este sondeo se interpretó como el efecto de un importante conductor metálico situado por debajo del fondo del sondeo, que fue intersectado entre $349.45 \mathrm{~m}$ y $370.15 \mathrm{~m}$ de profundidad, cuando se emplazó de nuevo el equipo de perforación en el sondeo MA-21 y se continuó la perforación hasta $530 \mathrm{~m}$.
\end{abstract}

Palabras clave: Descubrimiento, La Magdalena, Métodos geofísicos, Registros TEM en sondeos (Down-hole TEM), Sulfuros masivos.

\section{Discovery of the Magdalena ore body. The leading role of geophysical methods for the exploration of a deep volcanogenic massive sulphide deposits (VMS) in the Iberian Pyrite Belt}

\begin{abstract}
The Magdalena volcanogenic massive sulphide (VMS) deposit, located in the province of Huelva (Spain) and discovered by Minas de Aguas Teñidas S.A.U. (MATSA) in 2013 constitutes the largest discovery to be made in the Iberian Pyrite Belt (IPB) in recent decades. During a first phase of exploration, the deposit was discovered by drill testing a conductivity anomaly that was first detected during an airborne (helicopter) transient electromagnetic survey (VTEM) in 2011. Drill-hole MA-01 intersected the massive sulphide body at a depth of
\end{abstract}


between $225 \mathrm{~m}$ and $248 \mathrm{~m}$. Throughout the drilling campaign of the sulphide body later named "Masa 1", the drill holes were surveyed using Downhole TEM and Mise-à-la-Masse geophysical methods and during this work the Downhole TEM results from drill hole MA-21, which was originally drilled to $320 \mathrm{~m}$, detected the presence of a deeper and larger sulphide body. The appearance of an off-hole, down-hole TEM anomaly in hole MA-21 was fundamental in the discovery of "Masa 2" which was made once the drill rig was re-collared on the original MA-21 pad and drilled to a depth of $530 \mathrm{~m}$. This second sulphide lens ("Masa 2") was not detected by the initial VTEM survey because it was beyond the range for the system and was subsequently drill tested at depths between 350 and 1,000 m. The discovery of the Magdalena deposit has demonstrated the crucial role of certain geophysical methods for the detection of deep VMS deposits and confirms the prospectivity of the IPB as a metallogenic area of undoubted potential as far as the existence of similar deposits are concerned.

Keywords: discovery, down-hole TEM, geophysical methods, the Magdalena, massive sulphides.

\section{ABRIDGED ENGLISH VERSION}

\section{Geological framework}

The Magdalena deposit is located in the central, northern part of the IPB (Fig.1). The stratigraphic package is deformed from tectonic events resulting in a "disorder" of the units. The oldest rocks corresponding to the $P Q$ group appear thrusted over the VMS in the northern limits of the prospect. The VMS complex outcrops and is well developed. It comprises mainly volcanic rocks with the rare appearance of sediments and is where many of the sulphide deposits are hosted (Fig 2).

Figure 3 represents a typical cross section of the Magdalena deposit where the two polymetallic sulphide bodies are found: "Masa 1" (smaller and shallower) and "Masa 2", drill tested to date to a depth of 1,100 m.

\section{Geophysical exploration programme carried out at the Magdalena deposit}

In recent years there have been significant improvements in the sensitivity and precision of the results of gravimetric surveys, augmenting their capacity for detecting VMS deposits. Down-hole TEM is also a very efficient TEM method for evaluating the importance and continuity of massive sulphide bodies intersected by drill holes and identifying sulphide bodies located near or below the drill hole but not intersected by it. In addition to the TEM method, some traditional methods such as Mise-à-la-Masse are still frequently used in VMS exploration in the IPB.

\section{First phase of exploration using geophysical methods.}

Airborne (helicopter) TEM survey. Discovery of the Magdalena deposit

In 2011 an airborne survey using the versatile transient EM method (VTEM) was made. The geophysical data were collected by Geotech. An example of the results is shown in Figure 4.

The interpretation of the results allowed the definition of many geophysical anomalies that were later drill tested. One of these targets (drill hole MA-01) intersected a massive sulphide ore body, marking the discovery of the Magdalena deposit. Immediately after the discovery of this massive sulphide lens ("Masa 1"), new geophysical surveys were carried out to evaluate its continuity and to detect other nearby bodies.

Geophysical surveys conducted after the discovery of "Masa 1"

Mise-à-la-Masse - The first study using this method was carried out in drill hole MA-01.

The potential profile of Line $50 \mathrm{E}$ is presented in Figure 5 and shows the anomaly produced by the massive sulphide body and a contour map of all of the potential values. The principal conclusions are:

- Drill hole MA-01 intersected a massive sulphide mineralisation. The majority of the mineralisation extends to the east of the drill hole. It dips gently towards the north.

- The massive sulphide deposit extends over a distance of at least $300 \mathrm{~m}$ with an E-W strike direction.

These results significantly increase the information obtained in drill hole MA-01, contributing to the planning of the VMS deposit evaluation campaign. 
Ángel Granda Sanz, et al., 2019. El descubrimiento delYacimiento de la Magdalena... Boletín Geológico y Minero, 130 (2): $213-230$

Gravity - The Bouguer anomaly map obtained (Fig. 6) showed a gravity peak that correlates with the results of the Mise-à-la-Masse. The main conclusion was that the mineralisation intersected by MA-01 extended laterally to the east of the drill hole. The gravity anomaly is produced mainly by "Masa 1." "Masa 2" is difficult to detect in these measurements due to the near vertical orientation of the sulphides and their considerable depth. Subsequently the microgravity grid was enlarged to cover $22 \mathrm{~km}$. This new survey produced interesting results that permitted the definition of new anomalies as future drill targets.

Electric Resistivity Tomography - This survey was carried out to detect the effects of "Masa 1" or other similar targets, considering that the sulphide bodies may produce very low resistivity anomalies.

Figure 7 shows the resistivity section obtained in Line 100E. The conclusion of this test work is that the "Masa 12 massive sulphide deposit does not appear as a very low resistivity anomaly.

Magnetometry - The results of the airborne magnetometry carried out with the VTEM did not produce any anomaly over the Magdalena deposit (Fig. 4). MATSA performed a new ground survey with greater sensitivity. The results demonstrated again that the deposit has no magnetic response.

TEM Method Surface measurements - These surveys were done using two configurations: large size fixed loop (Turam) and smaller moving loop configuration (Slingram). See Table 1.

The Turam measurements generated an anomaly in the $Z$ component that corresponds to the effect of "Masa 1". For the moving loop configuration, the anomaly produced in the $Z$ component is the one from a tabular body with a sub-vertical dip. This modelled response is very similar to that obtained by the VTEM measurements (see Fig.4). The interference produced by some metal fences locally distorts the shape of the anomalies but does not mask the effects of "Masa 1" (Fig. 8). Later, an important exploration campaign was undertaken using a HT SOUID sensor because of its high sensitivity and stability.

Down-hole TEM - A systematic down-hole TEM survey was carried out in the majority of the holes drilled. The response of "Masa 1" was excellent (Fig. 9). The high conductivity of the sulphide bodies of the Magdalena is a favourable factor for generating off-hole anomalies in down-hole TEM. Figure 10 shows the TEM readings for drill hole MA-31; this hole intersected a narrow band of massive sulphides $(A)$ but did not intersect a second more important band $(B)$ located near the hole.

\section{The discovery of "Masa 2"}

During the systematic evaluation of the "Masa 1", MATSA drilled hole MA-21 to a depth of $320 \mathrm{~m}$. This hole did not intersect any massive sulphide mineralisation but the TEM measurements (Fig. 11) showed the presence of a deeper metallic conductor. The drill hole was continued and intersected a new massive sulphide body. In addition to the anomaly produced by massive sulphides intersected, these results identified a new off-hole TEM anomaly (Fig. 11). This proves the existence of another metallic conductor. Later drilling intersected a new independent ore body.

The interpretation of the down-hole TEM data was done using Maxwell software and integrating the information from all of the available drill holes (Fig. 12). Also noteworthy are the results of the Mise-à-la-Masse surveys from holes that intersected massive sulphides at depths greater than $400-450 \mathrm{~m}$. In this case (Fig. 13) we interpret that the conductor intersected by the drill hole is a northerly dipping body that extends towards the west.

\section{Final considerations and conclusions}

The discovery of the Magdalena VMS deposit is of great importance because it has demonstrated the efficiency of a well-planned and executed exploration programme. Correct selection and application of specific geophysical methods for detecting deep VMS deposits was one of the main factors that lead to its discovery.

The success of this project represents the possibility of discovering new deep VMS deposits in the Iberian Pyrite Belt. Success is possible when an exploration programme is designed correctly using the relevant methodology and the multi-skilled teams are well coordinated. As far as geophysical surveys are concerned, by using the correct methods and instrumentation it is possible to extend the exploration depth to around 1,000 m using surface methods and to some hundreds of metres using down-hole readings.

\section{Encuadre geológico y características generales del yacimiento de La Magdalena}

El yacimiento “La Magdalena” está situado en la parte norte y central de la Faja Pirítica Ibérica (Figura 1) encontrándose en este entorno concreto ampliamente representadas las tres unidades litoestratigráficas, definidas a nivel regional en la Faja Pirítica. Las dis- 


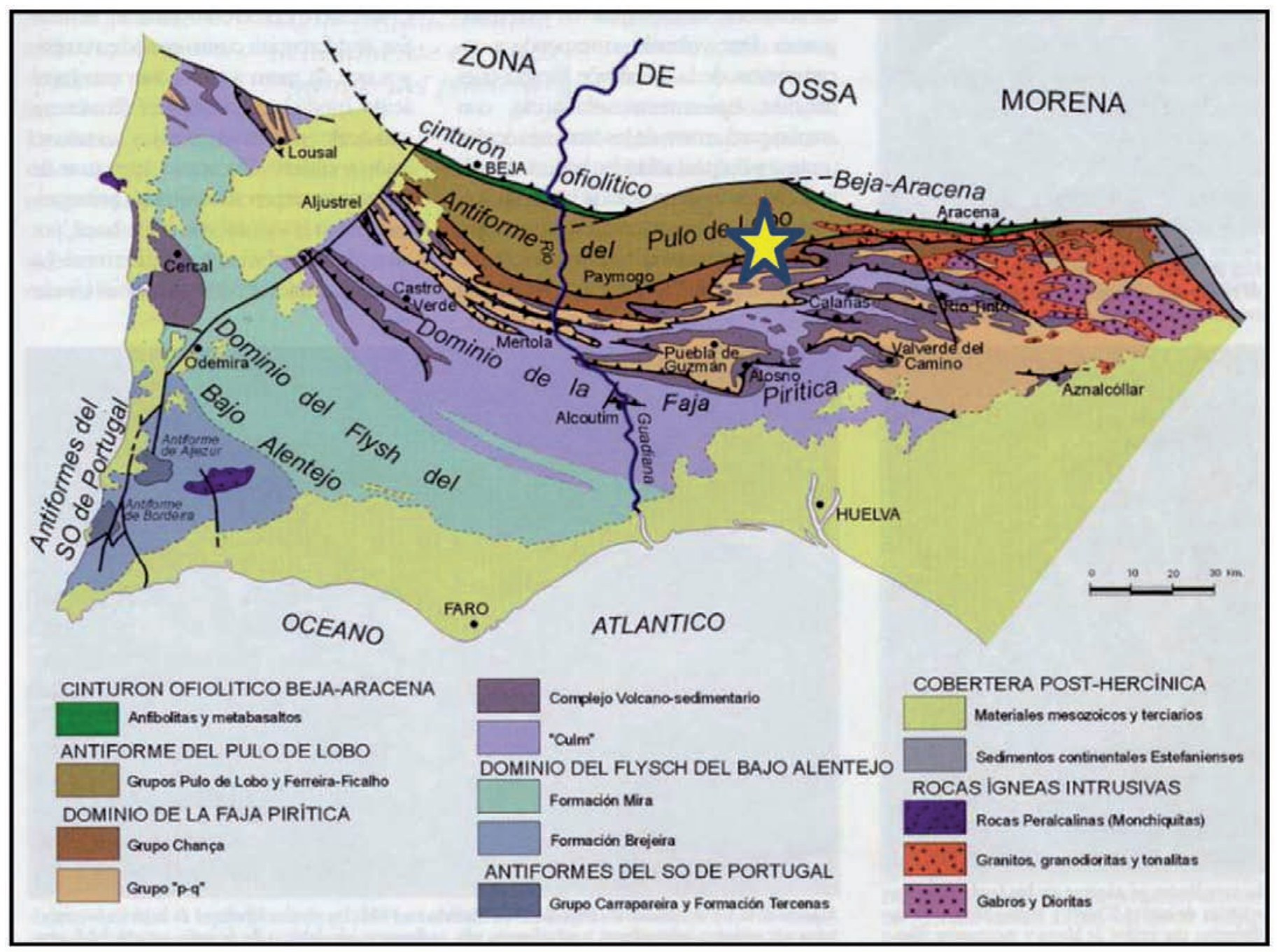

Figura 1. Localización del yacimiento La Magdalena en la Faja Pirítica Ibérica.

Figure 1. Location of the Magdalena deposits in the Iberian Pyrite Belt.

tintas etapas de deformación tectónica complican la disposición estratigráfica, apreciando en el mapa geológico del área cierto "desorden" reflejo de la complejidad tectónica. Así, los materiales más antiguos, correspondientes al Grupo PO del Devónico aparecen cabalgantes en el límite Norte de la zona concreta del Proyecto, así como en una estrecha banda en la mitad occidental del área de estudio, también como consecuencia de fenómenos tectónicos.

Al Sur, y fuera del área de La Magdalena aparecen ampliamente representados los materiales más modernos, correspondientes a las pizarras y grauvacas de facies Culm del Carbonífero Inferior. Entre ambas unidades, Devónico y Culm, el Complejo Volcanosedimentario se presenta ampliamente desarrollado y constituido fundamente por rocas volcáni- cas (lavas y piroclastos), con escasa representación de los términos sedimentarios. Es en esta formación donde se localizan diversas masas de sulfuros metálicos tales como Aguas Teñidas, Esperanza y La Magdalena. Hopgood y Hungerfrod corroboran esta información (1994).

La Figura 2 muestra una sección geológica característica del yacimiento de La Magdalena en la que se han incluido algunos sondeos representativos y las dos masas de sulfuros polimetálicos que forman el yacimiento: Masa 1 que es la de menor tamaño y que se localiza más superficial y Masa 2 reconocida hasta la fecha entre 350 y 1100 metros de profundidad. En términos geofísicos, ambos yacimientos de sulfuros polimetálicos pueden describirse como cuerpos tabulares de rumbo $\mathrm{E}-\mathrm{W}$ y buzamiento de $75^{\circ} \mathrm{N}$ aproximadamente. Sus principales características petrofísicas 


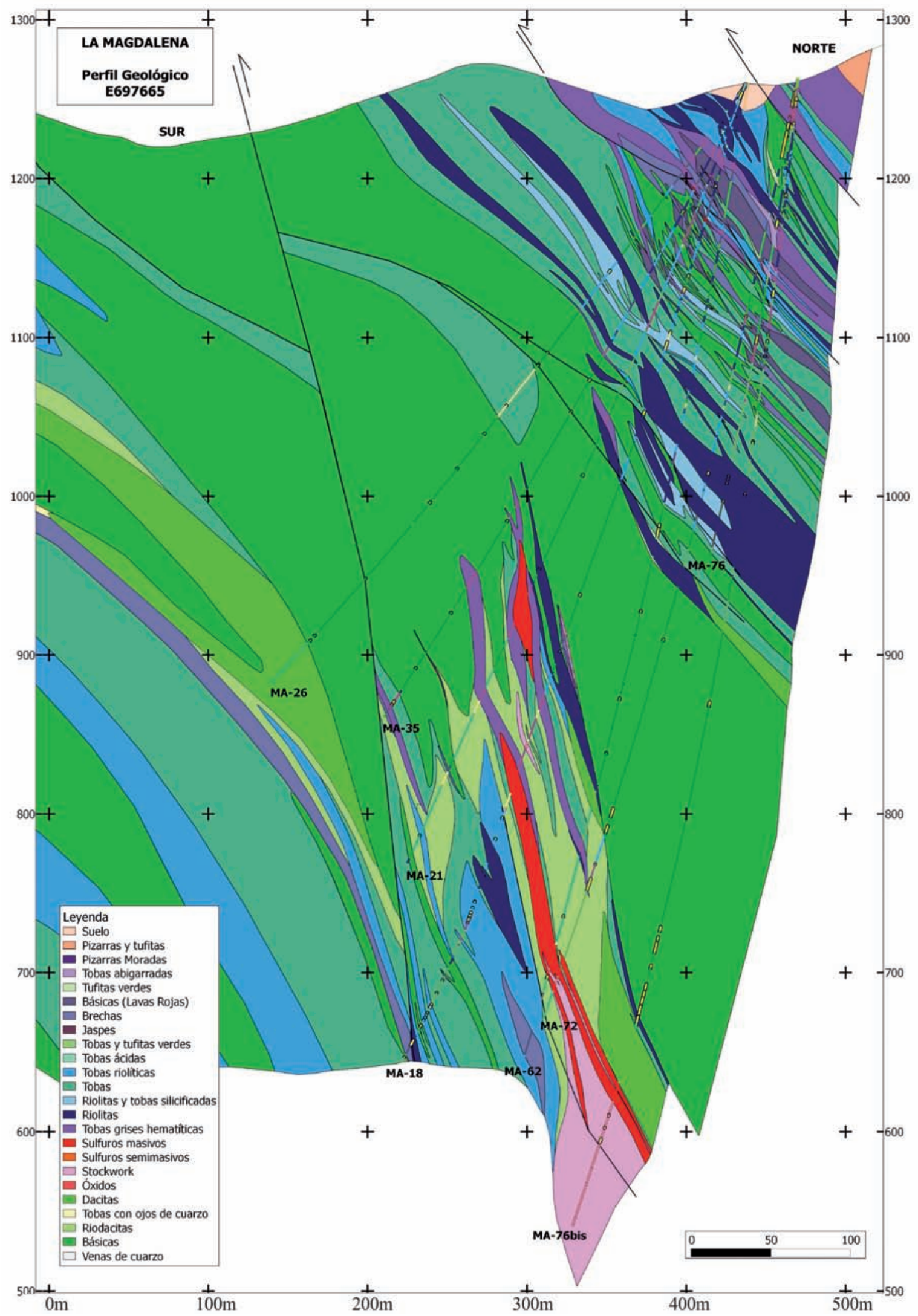

Figura 2. Sección geológica tipo del yacimiento de La Magdalena.

Figure 2. Typical geological cross section of the Magdalena deposit. 
en relación con el empleo de métodos geofísicos para su prospección, son altos valores de densidad y de Conductividad eléctrica en términos absolutos y en relación con las rocas encajantes.

\section{Programa de exploración mediante métodos geofísi- cos realizado en el área de La Magdalena. Consideraciones generales.}

Los programas de exploración geofísica para la detección de yacimientos de sulfuros polimetálicos masivos que se han venido aplicando habitualmente en la Faja Pirítica Ibérica durante decenas de años, se han basado en el hecho de que estos depósitos se caracterizan por su alta conductividad eléctrica $(>100$ $\mathrm{mS}$ ) y por su alta densidad $(>4 \mathrm{~g} / \mathrm{cc}$ ). La ausencia de minerales ferromagnéticos en una gran parte de estos yacimientos hace que su susceptibilidad magnética no sea muy diferente a la de las rocas encajantes. En consecuencia, el método Gravimétrico y las diversas variantes de métodos geofísicos basados en las medidas relacionadas con la resistividad eléctrica del terreno, se han demostrado de modo general como las herramientas geofísicas más efectivas para la detección de yacimientos de sulfuros metálicos masivos en la Faja Pirítica Ibérica, igual que en otras provincias metalogenéticas similares en todo el mundo con Hudson Bay en Canadá (Galley y Ames, 2014).

En los últimos años se han producido mejoras sustanciales en la sensibilidad y en la precisión de los resultados de los estudios geofísicos que contribuyen a incrementar su capacidad de detección de los depósitos VMS, extendiendo la exploración hasta $1000 \mathrm{~m}$ de profundidad como orden de magnitud. Entre estas mejoras cabe citar, en lo que respecta a la Gravimetría, el incremento de la sensibilidad de los gravímetros desde $0.01 \mathrm{mGal}$ hasta $0.001 \mathrm{mGal}$, la corrección del efecto del relieve por procedimientos automáticos a partir de modelos digitales del terreno y los avances en los procedimientos de modelización e inversión como herramientas auxiliares para la más completa interpretación de los resultados.

Los métodos electromagnéticos han adquirido un mayor protagonismo, y en concreto el método Electromagnético en Dominio de Tiempos (al que en este publicación nos referimos como TEM). Por su parte, entre las técnicas basadas en medidas por corriente continua merecen mención el método de la Tomografía Eléctrica, por ofrecer características muy interesantes en ciertos ámbitos de la exploración minera, y el método Mise-à-la-masse, que se sigue empleando con frecuencia y con éxito en la prospec- ción de yacimientos tipo VMS, debido a su eficacia para proporcionar información relativa a la continuidad de las masas de sulfuros metálicos cortados por los sondeos. A lo largo del proyecto de exploración de La Magdalena este método se ha empleado para el estudio del entorno de varios sondeos con resultados muy satisfactorios.

Es de destacar por su protagonismo en el descubrimiento y en la caracterización de La Magdalena el métodoTEM en su variante de las medidas en sondeos, porque permite resolver dos objetivos fundamentales y del mayor interés en cualquier proyecto de exploración de depósitos VMS, como son:

- Evaluar la importancia y la continuidad tanto lateral como en profundidad de los niveles de sulfuros metálicos masivos cortados por los sondeos.

- Identificar posibles niveles de sulfuros metálicos masivos que no hayan sido cortadas por los sondeos y que se localicen en su entorno o por debajo, con capacidad para extender el reconocimiento hasta distancias que superan habitualmente el centenar de metros desde el sondeo donde se realizan las medidas.

\section{Primera fase de la exploración del área de La Magdalena mediante métodos geofísicos. \\ Reconocimiento TEM aeroportado (VTEM) y descubri- miento del yacimiento de La Magdalena.}

En 2011, como parte del programa de exploración minera puesto en marcha por el equipo geológico de MATSA, se estudió mediante el método VTEM en su variante heliportada (según las recomendaciones expuestas por Scrivens en 2005), un área de $350 \mathrm{~km}^{2}$ seleccionada según criterios geológicos. Las medidas geofísicas se hicieron sobre perfiles de rumbo N-S separados entre 100 y $200 \mathrm{~m}$ y las especificaciones técnicas del estudio VTEM fueron las siguientes:

- Sistema TEM en configuración in-loop (off-time)

- Parámetros medidos, dBdtz, dBdtx, BfieldZ, BfieldX, Mag.

- Altitud del sensorTEM: $50 \mathrm{~m}$

- Altitud del sensor magnético: $70 \mathrm{~m}$

- Radio delTx: 17.5 m con 4 espiras

- Pico de corriente en el transmisor: $234 \mathrm{~A}$

- Momento magnético en el transmisor: 900.437 nIA

- Radio del receptor Z: $0.6 \mathrm{~m}$ y 100 espiras

- Radio del receptor X: 0.16 m y 245 espiras.

En la Figura 3 se presenta un ejemplo de los resultados de este estudio y en particular los de la línea 

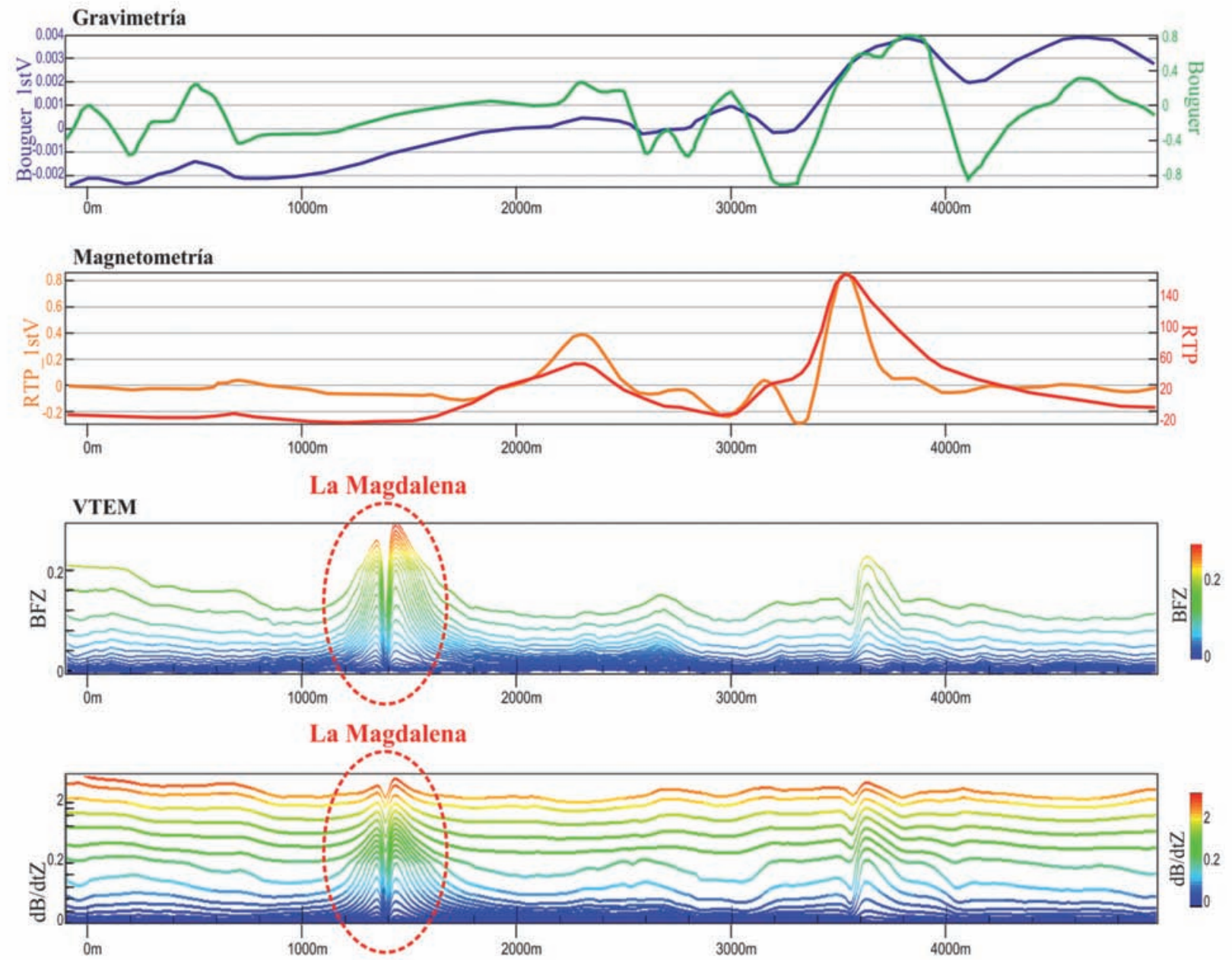

Figura 3. Sección de conductividad vs profundidad y perfiles multiparamétricos.

Figure 3. Conductivity depth image and multi-parameter profiles.

10360, que cruza sobre el yacimiento de La Magdalena. En esta presentación se incluyen también los resultados de los estudios gravimétricos realizados por diferentes organizaciones con anterioridad al estudio VTEM. Puede observarse con toda claridad el efecto de La Magdalena en los registros BFz y dBdtZ y también cabe señalar que este yacimiento no se manifiesta ni en las medidas gravimétricas antiguas ni en las medidas magnetométricas tomadas durante el estudio heliportado VTEM en el que el sensor magnético se situó a una altura media de $30 \mathrm{~m}$ sobre el suelo.

La interpretación de los resultados de este estudio, conjuntamente con la información geológica y geofísica preexistente, permitió la definición de varias anomalías geofísicas entre las que se seleccionaron las que se consideraron de mayor interés, para su posterior reconocimiento mediante sondeos. Una de estas anomalías fue reconocida en mayo de 2013 por el sondeo MA-01 que intersectó una masa de sulfuros metálicos entre $225 \mathrm{~m}$ y $248 \mathrm{~m}$ de profundidad. Este hecho se puede considerar como el descubrimiento del yacimiento La Magdalena.

Inmediatamente a continuación del descubrimiento de esta primera masa de sulfuros metálicos que posteriormente se denominó Masa 1, se llevaron a cabo nuevos estudios geofísicos para evaluar la continuidad de la mineralización y para tratar de detectar otras posibles masas de sulfuros metálicos en el entorno del sondeo MA-01.

\section{Estudios geofísicos realizados a partir del descubri- miento de la Masa 1}

MISE-À-LA-MASSE.- El primer estudio se realizó en el sondeo MA-01 y para ello se situó un electrodo de $\mathrm{Cu}$ a $230 \mathrm{~m}$ de profundidad en contacto con la masa de 
sulfuros metálicos y se hicieron las medidas de Potencial en modo gradiente con un espaciado de 20 m entre los electrodos MN, sobre 11 líneas de $800 \mathrm{~m}$ con rumbo N-S y separadas a intervalos de $100 \mathrm{~m}$.

Presentamos en la Figura 4 el perfil de potencial de la línea $50 \mathrm{E}$, con indicación de la anomalía producida por la masa de sulfuros metálicos y también incluimos el plano de isovalores de potencial que integra los resultados de este estudio. La interpretación que se hizo de estos resultados se resume en los siguientes puntos:

- El sondeo MA-01 intersectó a la mineralización (Masa 1) en la proximidad de su extremo occidental, es decir, que en su mayor parte el yacimiento se localiza hacia el este del sondeo.

- El nivel de sulfuros metálicos buza ligeramente hacia el norte, como demuestra el desplazamiento del máximo de potencial, que corresponde a la cabecera de la mineralización, hacia el sur del emboquille del sondeo.

- El nivel de sulfuros metálicos se extiende a lo largo de más de $400 \mathrm{~m}$ con rumbo este - oeste, tal como se puede interpretar en el plano de equipotenciales.
Estos resultados preliminares que se obtuvieron de forma inmediata a la finalización de la perforación del sondeo MA-01, ampliaron significativamente la información obtenida del referido sondeo y contribuyeron eficazmente a la programación de nuevos sondeos para completar el reconocimiento del yacimiento.

GRAVIMETRÍA. En una primera fase el estudio gravimétrico tuvo únicamente el carácter de ensayo metodológico ya que se limitó a una pequeña zona de $800 \times 800 \mathrm{~m}$ alrededor del sondeo MA-01. Los puntos de medida se distribuyeron en malla de $100 \times 50 \mathrm{~m}$ y para las medidas se empleó un microgravímetro modelo CG-5 Autograv. El plano de Anomalía de Bouguer obtenido (Figura 5) presenta un máximo gravimétrico en aceptable correspondencia con los resultados del estudio realizado mediante el método Mise-à-la-Masse, y en consecuencia la principal conclusión obtenida del ensayo microgravimétrico fue que la mineralización cortada por el sondeo MA-01 se extendía predominantemente hacia el Este del mismo.

Posteriormente el estudio microgravimétrico se amplió hasta cubrir un área de $22 \mathrm{~km}^{2}$ con más de 3000 puntos de medida. De este nuevo estudio se
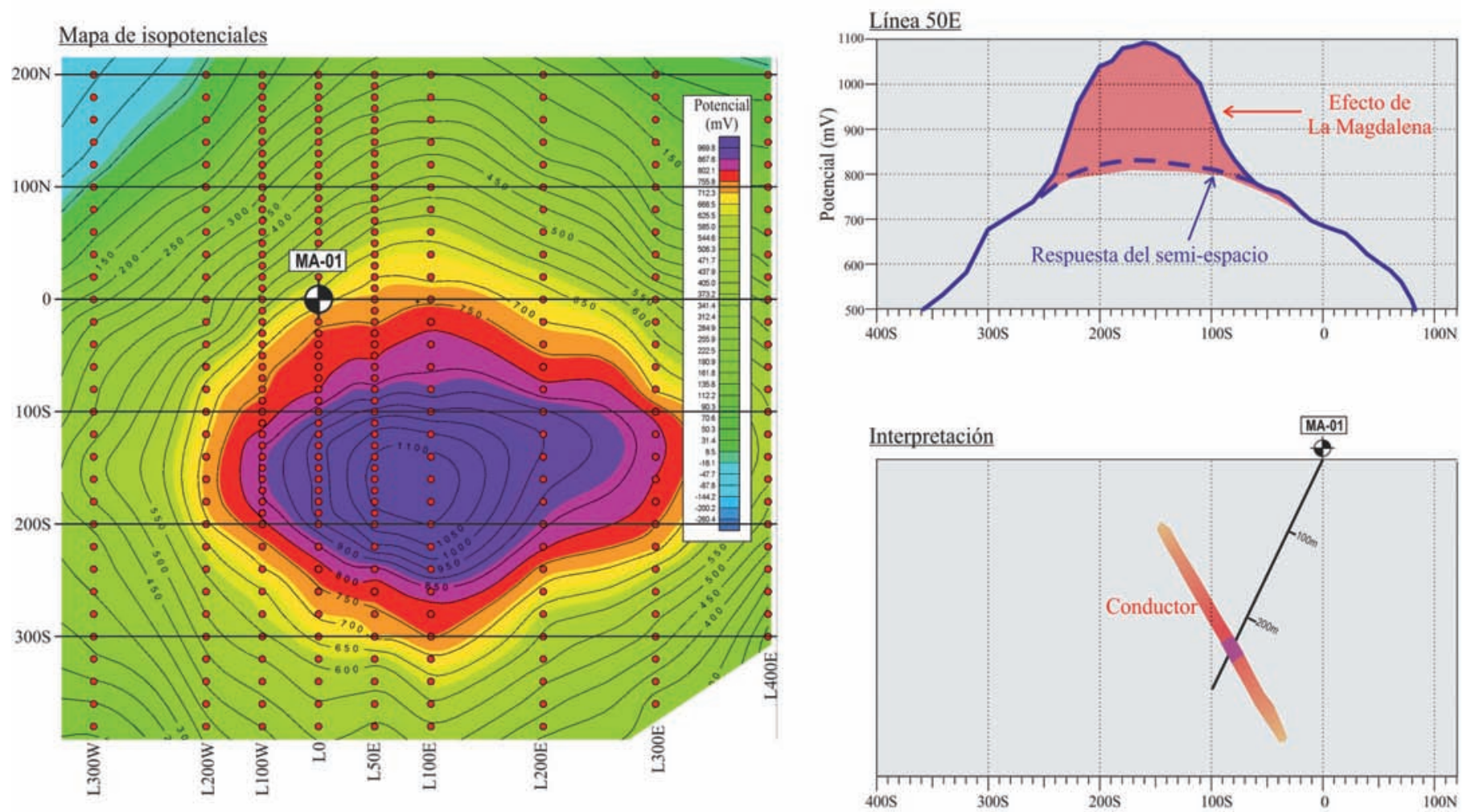

Figura 4. Resultados del estudio mediante Puesta a Masa en el sondeo MA-01. Figure 4. Results of the Mise-à-la-Masse survey of drill hole MA-01. 


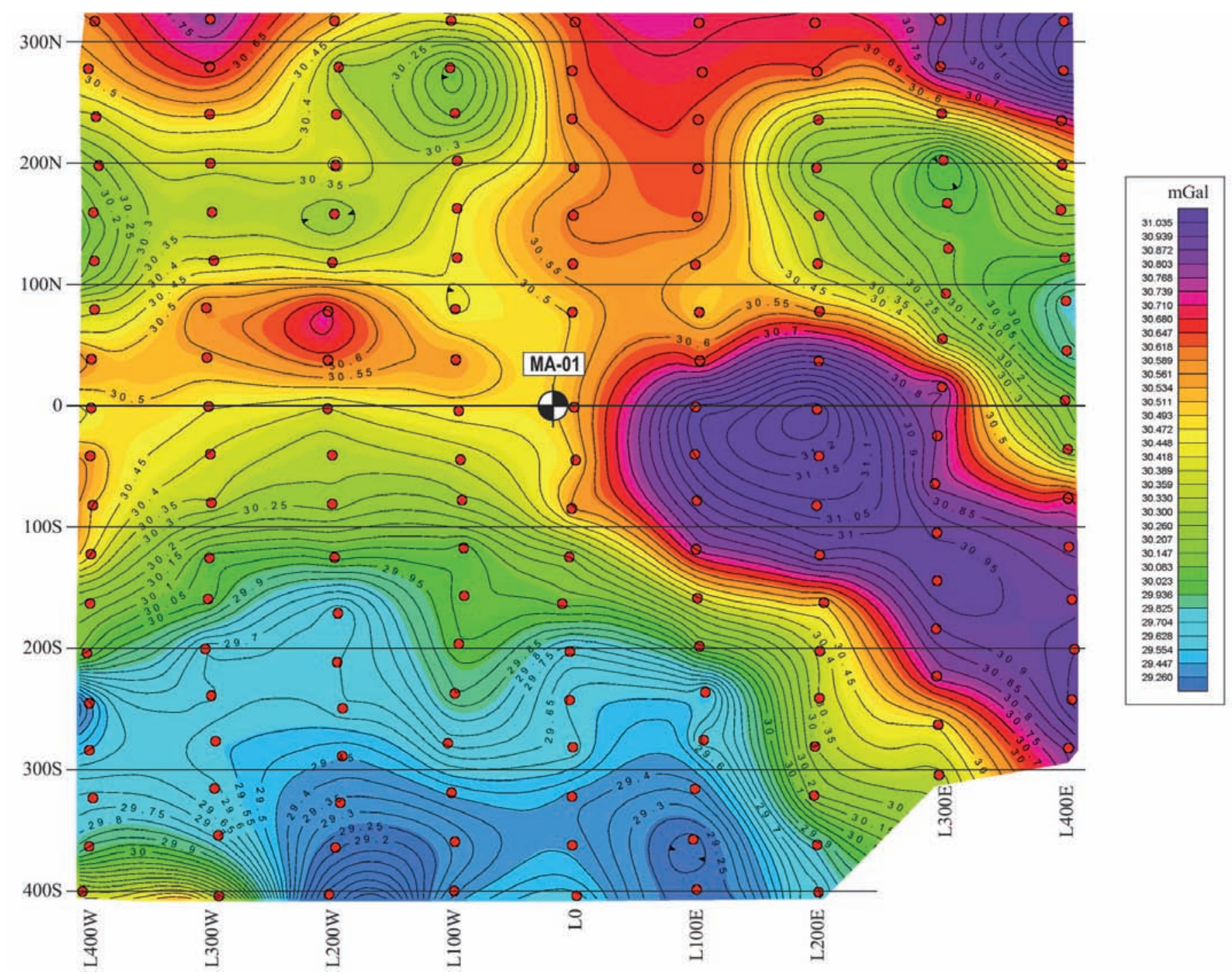

Figura 5. Plano de Anomalía de Bouguer.

Figure 5. Bouguer anomaly map.

obtuvieron otras conclusiones de interés que permitieron la identificación de algunas anomalías que a priori pueden constituir objetivos para su reconocimiento detallado mediante otros métodos geofísicos y mediante sondeos, si otros estudios posteriores mediante el método TEM permiten caracterizarlas como anomalías de alta Conductividad.

Nuestra interpretación de los resultados del estudio microgravimétrico es que la anomalía gravimétrica de La Magdalena es debida principalmente al efecto de la Masa 1. La Masa 2 resulta difícilmente detectable en estas medidas debido a su disposición subvertical y a la considerable profundidad a la que se localiza. Esta hipótesis se confirmó mediante un sencillo ejercicio de modelización cuyos resultados se presentan en la Figura 6.
El hecho de que en este ensayo gravimétrico la mineralización de La Magdalena produjera una anomalía gravimétrica positiva con una amplitud aparente del orden de $0.50 \mathrm{mGal}$ y, sin embargo, no exista una anomalía semejante en los datos gravimétricos antiguos, puede explicarse por la mayor sensibilidad del gravímetro utilizado para las nuevas medidas, por la mayor densidad de la malla de puntos de medida y tal vez por una corrección más precisa del efecto del relieve.

TOMOGRAFÍA ELÉCTRICA. También esta fase del estudio se realizó con carácter de ensayo metodológico, considerando que las masas de sulfuros metálicos deberían producir anomalías de baja Resistividad y que, empleando el dispositivo electródico adecuado, se podría alcanzar una profundidad de investiga- 

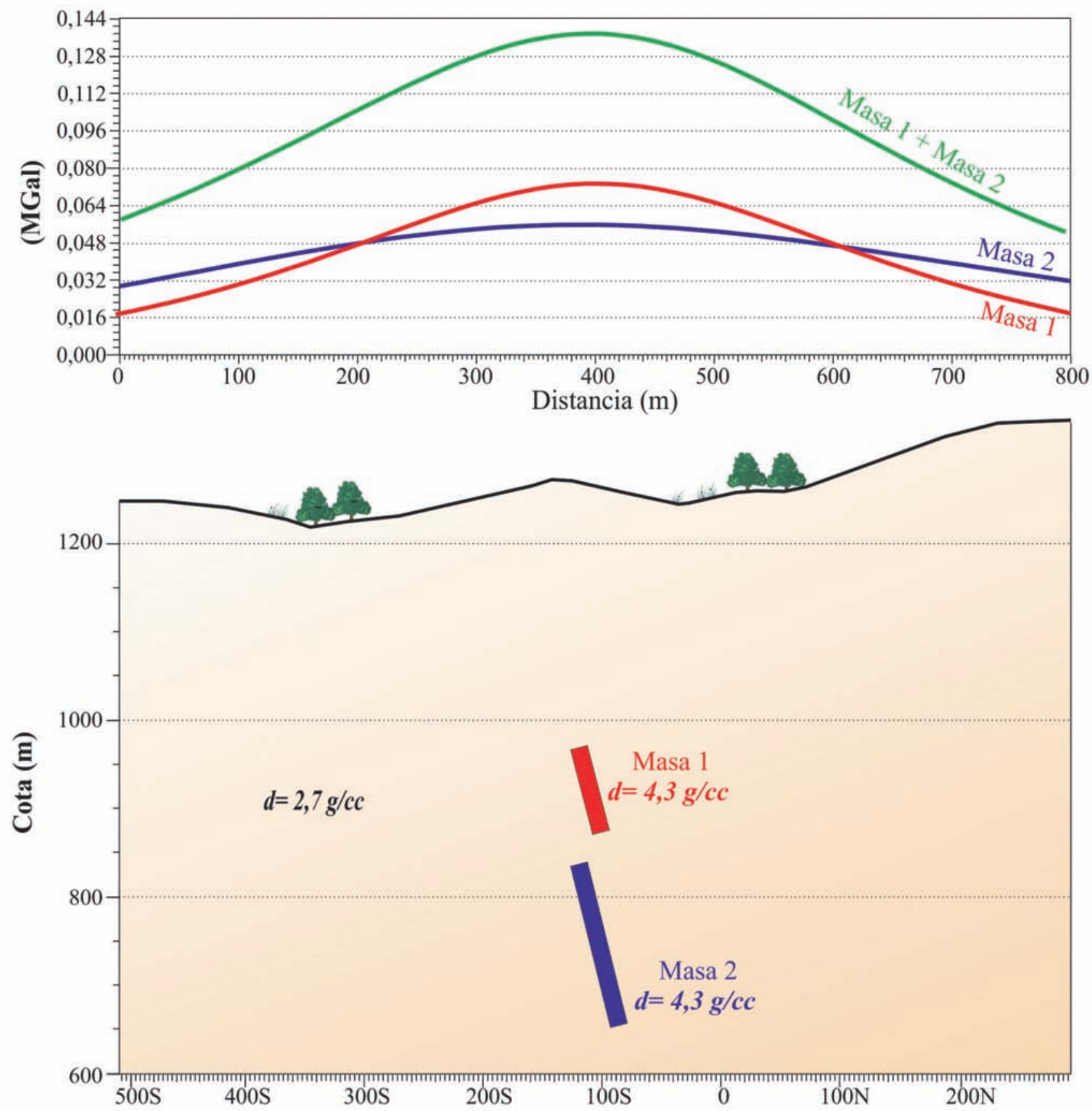

Figura 6. Modelos gravimétricos de la Masa 1 y la Masa 2.

Figure 6. Gravity models for "Masa 1" and "Masa 2."

ción de 300 a $350 \mathrm{~m}$ con suficiente resolución lateral como para identificar el efecto de la Masa 1, o de otras semejantes en la sección de resistividad resultante de la inversión de las medidas. Para estas medidas se empleó un sistema fabricado por Iris Instruments compuesto por un transmisor modelo VIP-3000 y un receptor ELREC Pro del tipo multidipolo, operando con un dispositivo electródico focalizado del tipo Polo - dipolo con una separación entre los electrodos, $a=20 \mathrm{~m}, \mathrm{y}$ con registro hasta 40 niveles de profundidad $(n=40)$.

La sección de resistividad obtenida en la línea $100 E$ de rumbo N-S, situada sobre la zona central de la Masa 1, se presenta en la Figura 7. En esta figura se incluyen como referencia las intersecciones de sulfuros masivos de dos sondeos (MA-02 y MA-05) y los registros TEM del sondeo MA-02. Los resultados de este ensayo ponen de manifiesto que la masa de sul- 

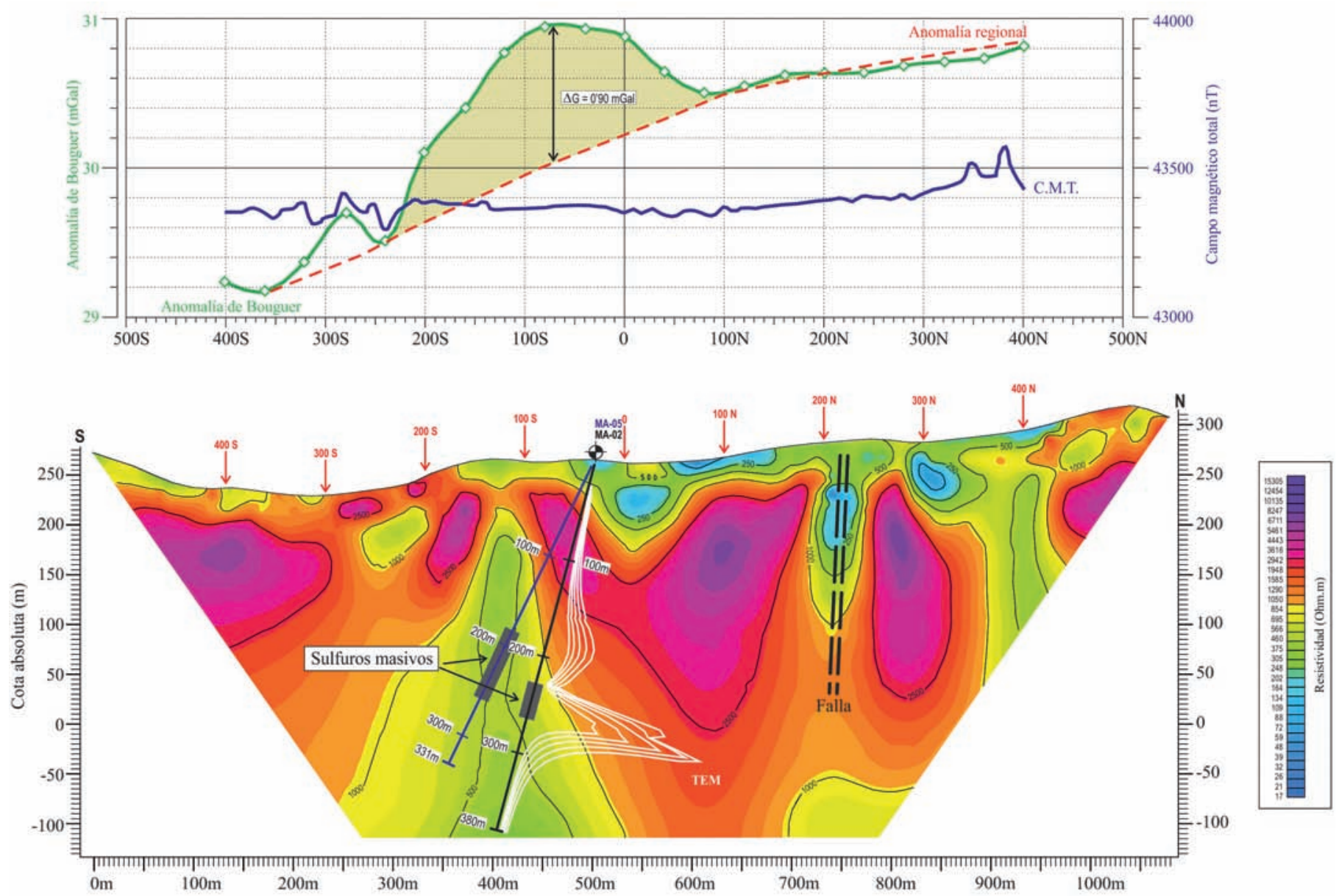

Figura 7. Sección de Resistividad obtenida mediante Tomografía Eléctrica en el perfil 100E.

Figure 7. Electrical Tomography Resistivity section for Line $100 \mathrm{E}$.

furos, Masa 1, no produce una anomalía de muy baja Resistividad, tal como a priori cabría esperar.

La intersección de sulfuros metálicos se localiza en esta sección dentro de una anomalía "conductora", pero el valor absoluto de la resistividad en ella es relativamente alto (aproximadamente $500 \mathrm{Ohm} . \mathrm{m}$ ). Es cierto que la resistividad de la roca encajante es muy alta ( $>2.000$ Ohm.m) en esta zona, y el contraste que representa la anomalía conductora es importante, pero en todo caso el efecto de la masa de sulfuros metálicos se manifiesta atenuado en los resultados del ensayo de Tomografía Eléctrica.

En nuestra opinión, contrastada con algún experto geofísico (Campbell, N. 2016), ello es debido a que pese a su alta conductividad, la potencia del nivel de sulfuros es muy pequeña, en términos relativos, en relación con la separación entre los electrodos del dispositivo de medida y con la profundidad a la que se localiza. Por otra parte, la capacidad resolutiva del método de la Tomografía Eléctrica, que decrece considerablemente al aumentar la profundidad. Los pro- cesos de inversión de datos para generar las secciones de resistividad pierden resolución con la profundidad y por ello tienden a distorsionar las anomalías producidas por conductores tabulares de pequeña potencia, en posición subvertical y de alta conductividad, haciéndolas más anchas y con menor contraste de Resistividad del que cabría esperar en función de los valores de resistividad reales de los sulfuros metálicos y de las rocas encajantes.

MAGNETOMETRÍA. Los resultados del reconocimiento aeromagnético realizado simultáneamente con las medidas VTEM no presentan ninguna anomalía sobre el yacimiento de La Magdalena (Figura 3). No obstante, MATSA decidió realizar un nuevo reconocimiento de mayor sensibilidad mediante medidas de superficie con un magnetómetro modelo GSM19TW, operando en modo continuo (walking mode). Este nuevo estudio confirmó los resultados anteriores demostrando que este yacimiento no tiene respuesta magnética, tal como se puede observar en las medidas del Perfil 100E que presentamos conjunta- 
mente con la sección de Resistividad y el perfil de Anomalía de Bouguer en la Figura 7.

MÉTODO TEM. MEDIDAS EN SUPERFICIE. En estos ensayos se operó con las dos modalidades habituales para las medidas TEM: Empleando un bucle fijo de gran tamaño (modo Turam) y en la modalidad de bucles móviles de pequeño tamaño (modo Slingram). En todos los casos se utilizó para las medidas un sistema PROTEM (receptor para medidas EM con 20 ventanas de tiempo que permite medir las tres componentes del campo EM secundario creado al inyectar corriente eléctrica a través de un bucle transmisor) y como sensor se empleó una bobina de inducción sin preamplificador y con un área equivalente de $100 \mathrm{~m}^{2}$. Ambas unidades están fabricadas por Geonics. Las especificaciones técnicas de las medidas realizadas en ambas modalidades se resumen en la Tabla 1.

\begin{tabular}{|c|c|c|}
\hline & Turam & Slingram \\
\hline Tamaño del bucle Tx & $700 \times 400 \mathrm{~m}$ & $100 \times 100 \mathrm{~m}$ \\
\hline Sincronismo Tx $-\mathrm{Rx}$ & Mediante cristal & $\begin{array}{c}\text { Cable de referen- } \\
\text { cia }\end{array}$ \\
\hline Intensidad de los pulsos & $15.5 \mathrm{~A}$ & $22 \mathrm{~A}$ \\
\hline $\begin{array}{c}\text { Tiempo de corte de los } \\
\text { pulsos }\end{array}$ & $295 \mu \mathrm{s}$ & $75 \mu \mathrm{s}$ \\
\hline $\begin{array}{c}\text { Parámetro medido } \\
\text { Frecuencia de los pulsos }\end{array}$ & $\begin{array}{c}\text { Hos componen- } \\
\text { (Z,X) del campo } \\
\text { EM transitorio. }\end{array}$ & $\begin{array}{c}\text { Dos componen- } \\
\text { tes ortogonales } \\
\text { (Z,X) del campo } \\
\text { EM transitorio. }\end{array}$ \\
\hline Modalidad de medida & Off-time & $\begin{array}{c}\mathrm{HI} \text { (25 Hz) \& MD } \\
\text { (6.25 Hz) }\end{array}$ \\
\hline
\end{tabular}

Tabla 1. Especificaciones de las medidas TEM de superficie.

Table 1. Technical specifications for the surface TEM survey.

En las medidas Turam el bucle transmisor se situó desplazado algunos centenares de metros hacia el norte de la mineralización con el fin de conseguir un buen acoplamiento EM entre el campo primario y un conductor de morfología tabular en disposición subvertical o con un ligero buzamiento hacia el norte, tal como se habían interpretado los resultados del estudio Mise-à-la-Masse realizado en el sondeo MA-01.

Las medidas TEM de superficie presentan una anomalía en su componente $Z$ que corresponde al efecto de la Masa 1 de La Magdalena y se manifiesta principalmente en los canales $6-15$ de la frecuencia HI (25 $\mathrm{Hz}$ ), entre 0.240 y $2.19 \mathrm{~ms}$. En las medidas obtenidas en modo Turam la anomalía consiste en un máximo en los valores de la f.e.m del campo EM transitorio, perfectamente identificable.
En las medidas obtenidas con dispositivo de bucles móviles la anomalía producida en las medidas de la componente $\mathbf{Z}$ por un conductor de morfología tabular en disposición subvertical está formada por un mínimo situado sobre la cabecera del conductor, flanqueado por dos máximos. Este modelo de respuesta es identificable en las medidas realizadas en este ensayo en la línea 100E con rumbo N-S que se localiza sobre la zona central de la Masa 1 y es muy similar al obtenido en las medidas VTEM (ver Figura 4). La interferencia producida en las medidas TEM por algunas vallas metálicas existentes en la zona de estudio y en su entorno, distorsiona localmente la morfología de las anomalías, pero no llega a enmascarar el efecto de la Masa 1 que se puede reconocer fiablemente (Figura 8) en los registros TEM.

Los resultados de estos ensayos confirman la eficacia del método TEM para detectar niveles de sulfuros metálicos del tipo de la Masa 1. Su aplicación para extender el reconocimiento hasta $1000 \mathrm{~m}$ de profundidad, es factible aumentando el momento magnético transmitido al terreno y empleando sensores especiales de alta sensibilidad para poder registrar señales de pequeña amplitud representativas del efecto de los niveles más profundos.

En consecuencia, con posterioridad a la evaluación del yacimiento de La Magdalena, se llevó a cabo una importante campaña de reconocimiento en otras zonas próximas seleccionadas por el Departamento de Exploración de MATSA. El objetivo de esta campaña fue la detección de otros posibles yacimientos profundos del tipo VMS y para ello se empleó el métodoTEM operando en modo Turam con bucles de gran tamaño ( $2 \mathrm{~km} \times 1 \mathrm{~km}$ ) en los que se hicieron circular pulsos de corriente de $20 \mathrm{~A}$. Para mejorar la sensibilidad de los registros se empleó un sensor del tipo HT SQUID, que es actualmente la instrumentación más avanzada para medidas TEM en superficie (Le Roux y Macnae, 2007).

MÉTODOTEM. MEDIDAS EN SONDEOS. La ejecución de registros TEM se llevó a cabo de modo sistemático en una gran parte de los sondeos que se perforaron para la evaluación del yacimiento, porque se pudo comprobar que estas medidas proporcionaban información de interés para definir la continuidad de los niveles de sulfuros metálicos intersectados por los sondeos y para identificar otras posibles masas metálicas situadas en su proximidad.

Para el estudio de cada sondeo se eligió cuidadosamente la localización del bucle transmisor con el fin de conseguir el máximo acoplamiento del campo EM primario con las posibles masas de sulfuros metálicos del entorno del sondeo. En algún caso se estudió algún sondeo empleando varios bucles transmisores 
Dispositivo Slingram - Frecuencia $25 \mathrm{~Hz}$

Componente Z - Canales \#10-20

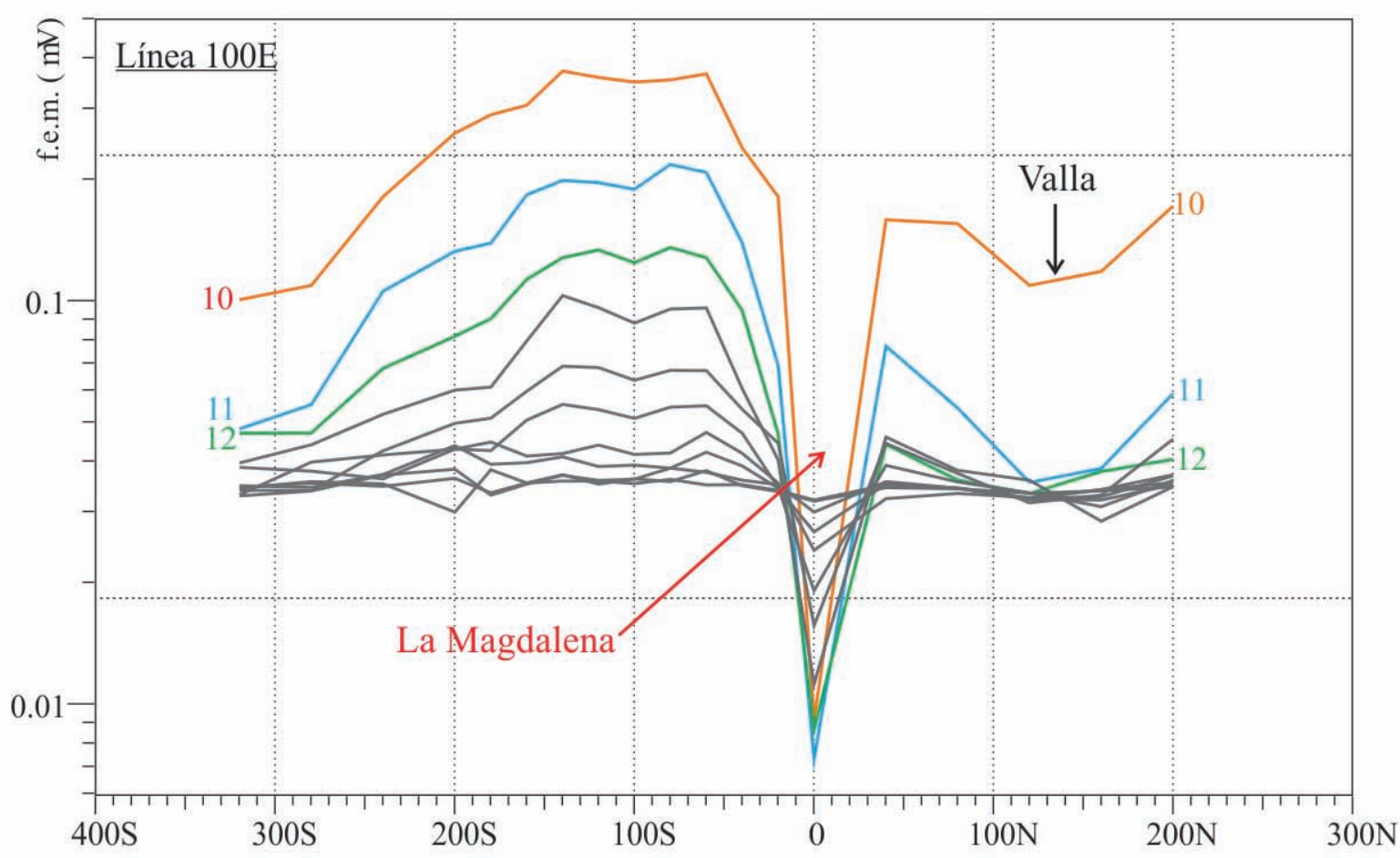

Figura 8. Ejemplo de resultados del reconocimiento TEM de superficie.

Figure 8. Example of results from ground TEM survey.

convenientemente situados. Asimismo el tamaño de cada bucle y la intensidad de los pulsos de corriente se eligieron de modo que el momento magnético transmitido al terreno fuera muy intenso (mayor de $\left.1500000 \mathrm{Am}^{2}\right)$. Se empleó para las medidas un sistema PROTEM con un transmisor tipoTEM-67 y con una sonda modelo $\mathrm{BH}-49-3 \mathrm{D}$ de tres componentes $(X, Y, Z)$ $y$ en cada sondeo se hicieron dos series de registros para las frecuencias $\mathrm{HI}(25 \mathrm{~Hz})$ y $\mathrm{MD}(6.25 \mathrm{~Hz})$ de los pulsos de corriente en el bucle transmisor con el fin de extender el reconocimiento desde la proximidad inmediata del sondeo hasta la máxima distancia posible, que calculamos fue del orden de 150 m (Duncan, 2014).

La respuesta de la mineralización de La Magdalena fue excelente en estos registros en todos los sondeos estudiados. A modo de ejemplo, presentamos en la Figura 9 los registros del sondeo MA-01 que tienen la particularidad de que la anomalía producida por el nivel de sulfuros masivos intersectado entre 225 y $248 \mathrm{~m}$ cambia de polaridad a partir de los canales 14-15 de la frecuencia HI. Este cambio de polaridad es indicativo de que el sondeo cortó la mineralización lejos de su zona central y relativamen- te próxima a su borde superior, tal como se ha comprobado mediante modelización utilizando el software Maxwell y mediante los resultados de los sondeos que se perforaron a continuación.

La alta conductividad de las masas de sulfuros metálicos de La Magdalena es un factor favorable para la generación de anomalías tipo off-hole en las medidas TEM producidas por otros niveles de sulfuros metálicos no cortados por los sondeos y situados en su proximidad, como es el caso del sondeo MA-31 cuyos registros TEM presentamos en la Figura 10. Este sondeo intersectó un pequeño nivel de sulfuros (A) pero no intersectó un nivel (B) de mayor importancia localizado a algunas decenas de metros del sondeo.

\section{Descubrimiento de la Masa 2}

Durante la campaña de reconocimiento sistemático de la Masa 1 mediante sondeos y con el objetivo de estudiar su continuación hacia el Este, MATSA perforó el sondeo MA-21 hasta una profundidad de $320 \mathrm{~m}$. Este sondeo no intersectó ningún nivel de sulfuros 
Ángel Granda Sanz, et al., 2019. El descubrimiento del Yacimiento de la Magdalena... Boletín Geológico y Minero, 130 (2): $213-230$

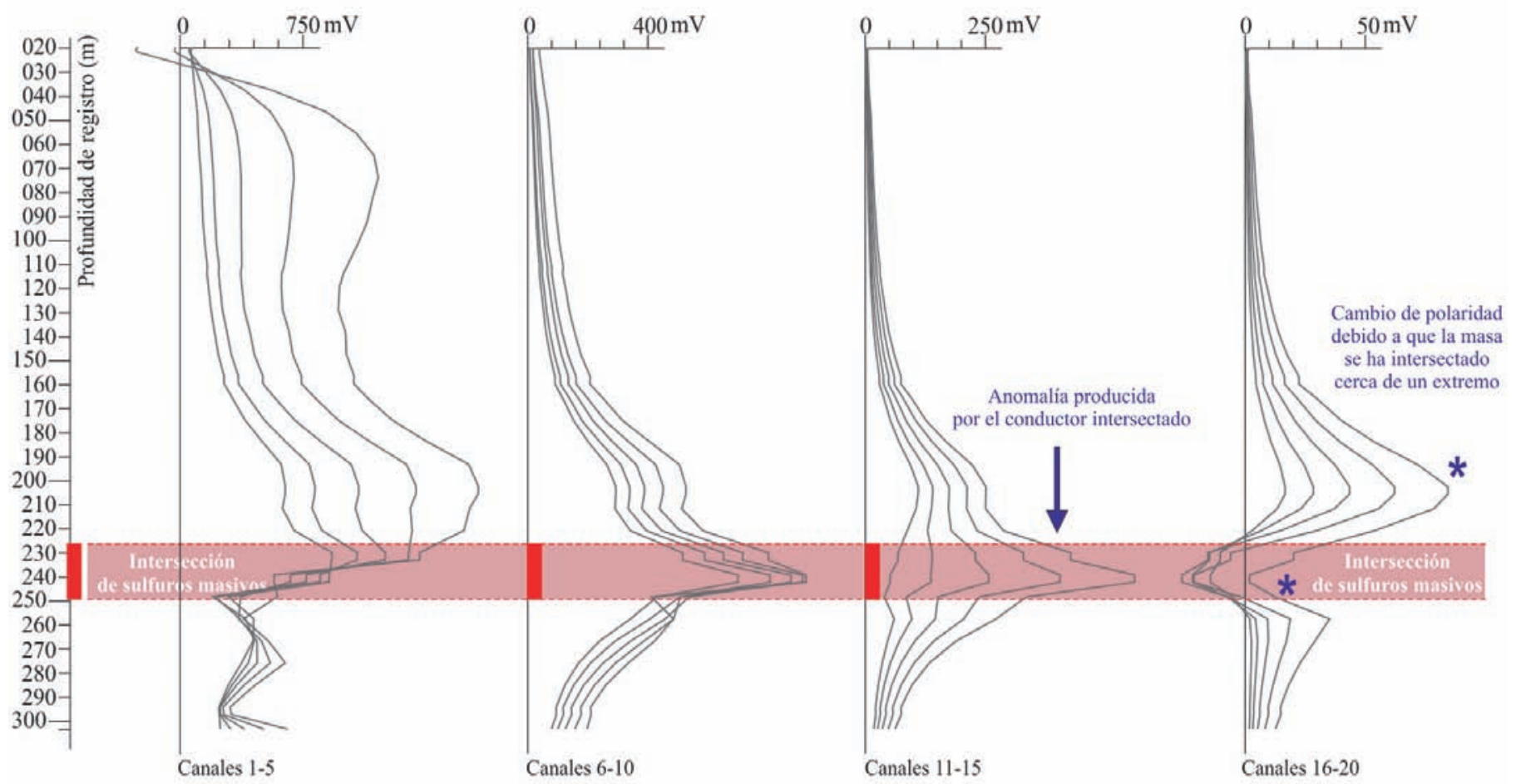

Figura 9. Registros TEM obtenidos en el sondeo MA-01, canales \#1-20, frecuencia $25 \mathrm{~Hz}$.

Figure 9. DHEM data for drill hole MA-01, channels \#1-20, base frequency $25 \mathrm{~Hz}$.

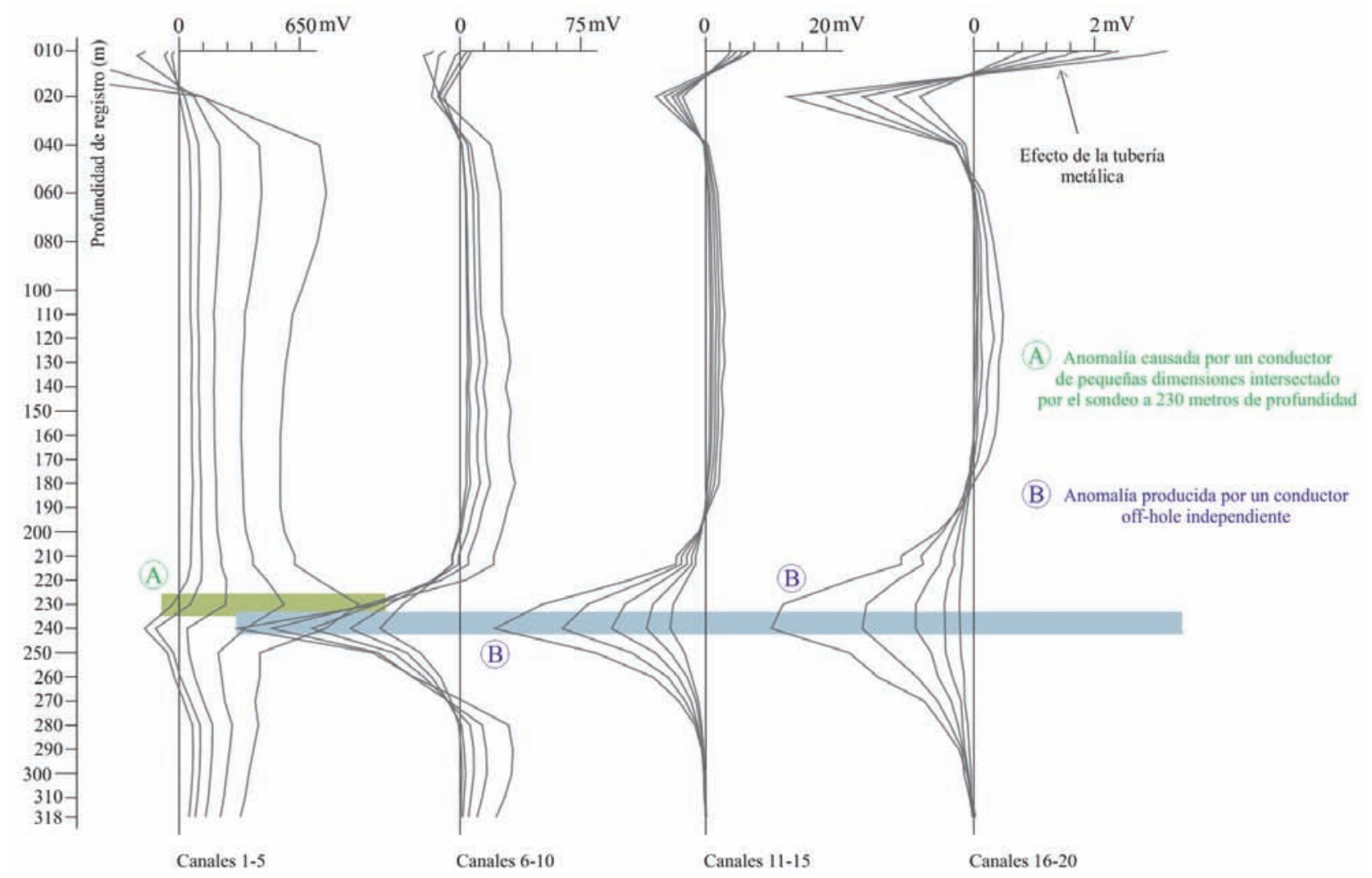

Figura 10. Ejemplo de una anomalía off-hole causada por un conductor próximo al sondeo MA-31.

Figure 10. Example of an off-hole anomaly caused by a conductor close to drill hole MA-31. 
metálicos, pero los registros TEM (Figura 11) que se realizaron en él el día 8 de Julio de 2013, pusieron de manifiesto una interesante anomalía que de forma incuestionable se pudo interpretar como el efecto de un conductor metálico situado por debajo del sondeo. El equipo de IGT comunicó inmediatamente
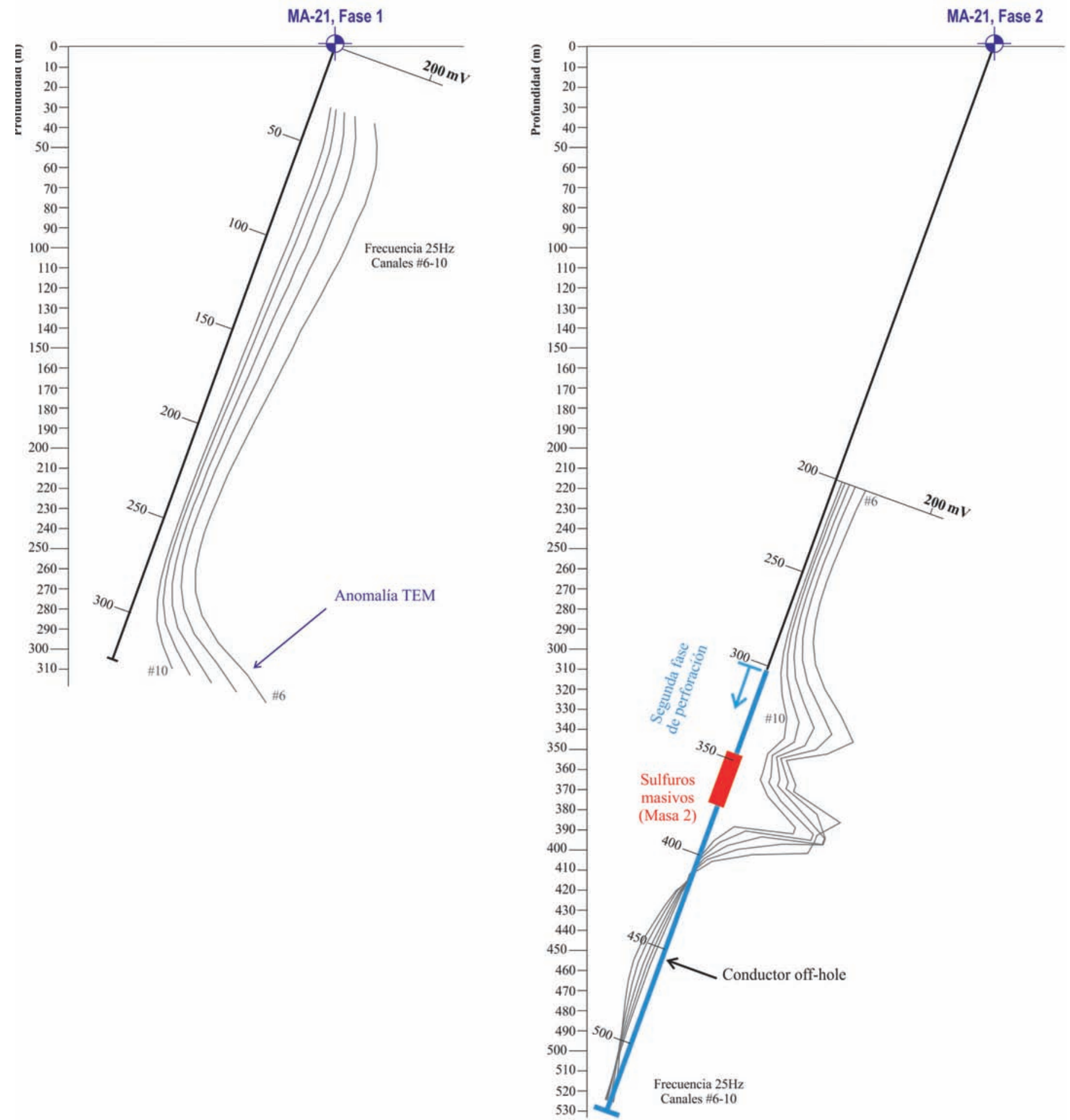

Figura 11. Registros TEM obtenidos en el sondeo MA-21, fases 1\&2. Descubrimiento de La Magdalena "Masa 2". Figure 11. TEM records from drill hole MA-21, phases 1\&2. Discovery of the Magdalena "Masa 2". 
estos resultados al Departamento de Exploración de MATSA con la recomendación de emplazar de nuevo la máquina de sondeos para continuar la perforación del sondeo MA-21. MATSA siguió esta recomendación y el resultado fue que se intersectó una nueva masa de sulfuros metálicos a lo largo de $20.7 \mathrm{~m}$, entre $349.45 \mathrm{~m}$ y $370.15 \mathrm{~m}$.

Al finalizar la perforación a $530 \mathrm{~m}$ de profundidad, se hicieron nuevos registros TEM en el sondeo MA-21 desde $200 \mathrm{~m}$ hasta el fondo del sondeo. En ellos (ver Figura 11), además de la anomalía producida por el nivel de sulfuros metálicos intersectados entre 349.45 $\mathrm{m}$ y $370.15 \mathrm{~m}$, se identifica otra anomalía TEM de tipo off-hole centrada a $460-470 \mathrm{~m}$ de profundidad que pone de manifiesto la existencia de otro posible conductor metálico no cortado por el sondeo y situado relativamente alejado del mismo. Otros sondeos posteriores intersectaron el nivel de sulfuros metálicos que produjo esta anomalía y que es independiente del cortado entre $349.5 \mathrm{~m}$ y $370.15 \mathrm{~m}$ por el sondeo MA-21.

El estudio de la continuidad de la Masa 2 se llevó a cabo mediante una importante campaña de sondeos, en varios de los cuales se realizaron estudio geofísicos Mise-à-la-Masse y registros TEM en otros. La información obtenida de estos estudios contribuyó a que el equipo geológico de MATSA optimizara la campaña de sondeos y a que pudiera interpretar de

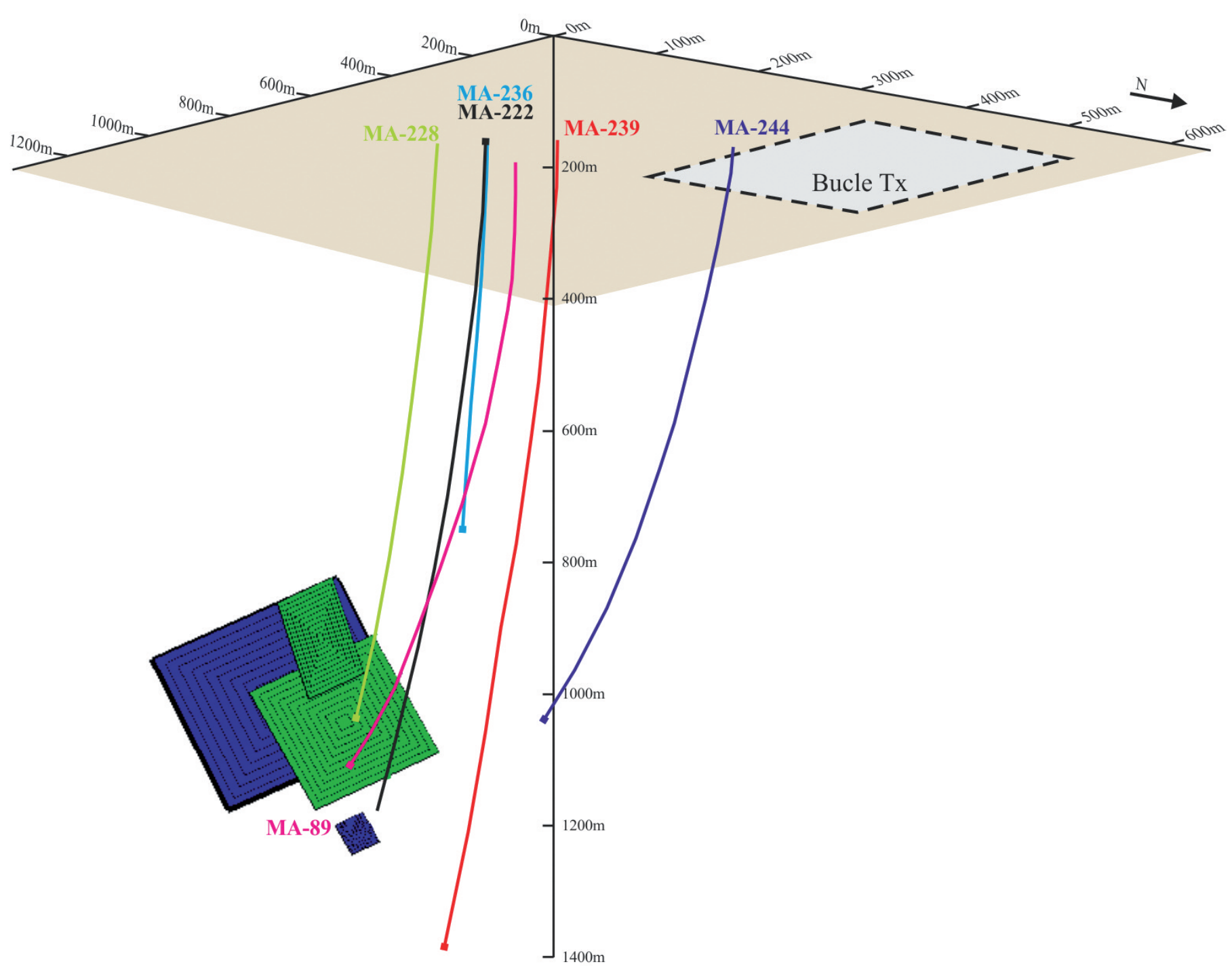

Figura 12. Imagen 3D con los resultados del proceso de interpretación de registros TEM en sondeos, modelizados utilizando el software Maxwell de EMIT.

Figure 12. Typical 3D image showing the output of the interpretation process of a DHEM data set after modelling using EMIT Maxwell software. 
forma más precisa algunas características del yacimiento de La Magdalena, cuya descripción detallada queda fuera del alcance de esta publicación.

La interpretación de los registros TEM obtenidos en los sondeos se realizó mediante modelización empleando el software Maxwell e integrando la información de todos los sondeos disponibles con el fin de reducir la ambigüedad de los resultados, que se presentaron en forma de imágenes 3D del tipo de la Figura 12. Esta figura corresponde a una serie de sondeos localizados en un sector del yacimiento en el que la mineralización de sulfuros metálicos se localiza a más de $800 \mathrm{~m}$ de profundidad.

Por otra parte, es interesante la experiencia de los estudios Mise-à-la-Masse realizados en sondeos en los que los sulfuros metálicos se intersectaron a profundidades mayores de $400-450 \mathrm{~m}$ como es el caso del sondeo MA-161. Habitualmente se consideraba que este método se limitaba al estudio de mineralizaciones relativamente superficiales, hasta $250-300 \mathrm{~m}$ de profundidad, porque cabía esperar que el efecto conductor de la masa de sulfuros metálicos quedara atenuado notablemente por la influencia del macizo rocoso de carácter resistivo situado por encima de ella. Sin embargo, en todos los casos estudiados se pudo comprobar que el máximo de potencial producido por los sulfuros metálicos resultaba identificable en el plano de isovalores de potencial y permitía interpretar la continuidad lateral del conductor. Este es el caso del ejemplo que presentamos en la Figura 13 obtenida del estudio del sondeo MA-161, donde los resultados obtenidos de este estudio permiten interpretar que el conductor cortado por este sondeo buza hacia el norte, que se extiende principalmente hacia el Oeste y que su extremo oriental se localiza alrededor del perfil 800E. Este tipo de conclusiones fueron de indudable interés en la exploración del yacimiento de La Magdalena.

\section{Conclusiones y consideraciones finales}

El descubrimiento del yacimiento VMS de La Magdalena tiene importancia desde el punto de vista

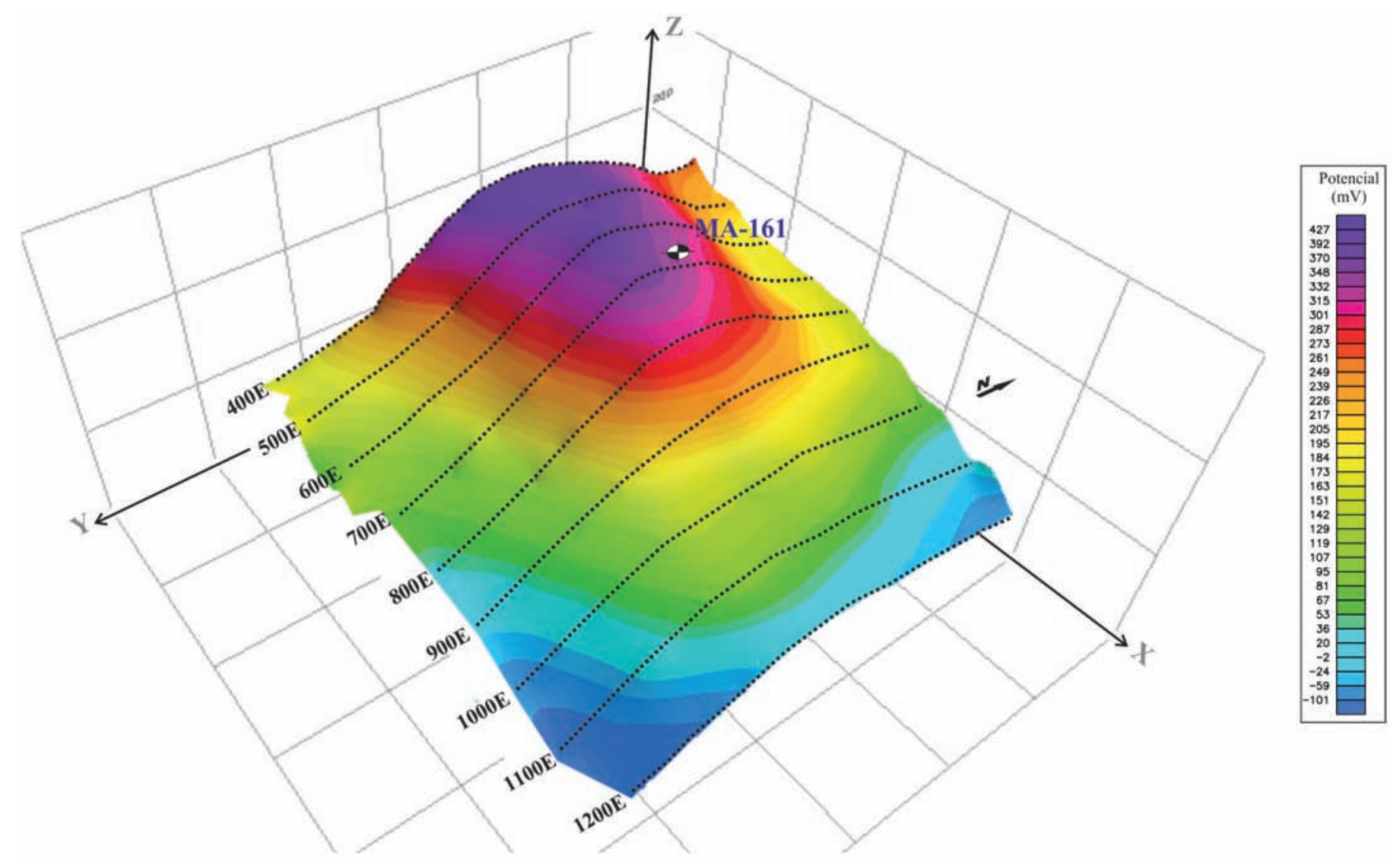

Figura 13. Imagen 3D del plano de potencial del estudio mediante Puesta a Masa en el sondeo MA-161.

Figure 13. 3D image of the potential map resulting from the Mise-à-la-Masse survey for drill hole MA-161. 
metodológico porque ha permitido demostrar la eficacia de un programa de prospección correctamente planteado y ejecutado. El primer paso de este proceso ha sido la selección de las zonas de estudio por criterios geológicos realizada por el Departamento de Exploración de MATSA. A partir de este punto, la correcta selección y aplicación de los métodos geofísicos específicos en cada fase del proyecto ha sido un factor determinante que ha llevado al descubrimiento del yacimiento de La Magdalena.

En nuestra opinión, el éxito de este proyecto tiene un significado que va más allá de sus resultados puntuales y es que representa la confirmación de que están abiertas las posibilidades de descubrir nuevos yacimientos de depósitos profundos tipo VMS en la Faja Pirítica Ibérica cuando se desarrolla completamente un programa de exploración ambicioso en sus objetivos y en su planteamiento, dirigido y coordinado por un equipo geológico experto que integre el correcto empleo de los métodos geofísicos adecuados. En el momento actual se dispone de métodos geofísicos fiables que pueden extender la exploración hasta más de $1000 \mathrm{~m}$ de profundidad mediante medidas de superficie y hasta algunos centenares de metros más a partir de medidas en sondeos. Los resultados de los estudios realizados en otros yacimientos VMS en todo el mundo, y específicamente en La Magdalena así lo demuestran.

\section{Agradecimientos}

La oportunidad de haber participado en este proyecto es para los autores de este artículo un motivo de orgullo y también de agradecimiento a MATSA por su confianza en nuestro trabajo.

\section{Referencias}

Campbell, N. 2016. Resource Potentials - Australia. Comunicación personal.

Duncan, A. 2014. Digiatlantis Borehole TEM at Lalor. British Columbia Geophysical Society. Exploration for Deep VMS Ore Bodies. The Hudbay Lalor Case Study.

Galley, A. and Ames, D. 2014. Important characteristics of VMS deposits for deep exploration. British Columbia Geophysical Society. Exploration for Deep VMS Ore Bodies. The Hudbay Lalor Case Study.

Hopgood, D. and Hungerford, N. 1994. Geophysical case history of the discovery of the Aguas Teñidas East massive sulphide deposit, SW Spain. Exploration Geophysics 25 (1) 1-17.

Le Roux, C and Macnae, J. 2007. SOUID Sensors for EM systems. Proceedings of Exploration 07: Fifth Decennial International Conference on Mineral Exploration. 417-423.

Scrivens, S. 2005. A comparison between Helicopter and Fixed-Wing Time Domain Electromagnetic Systems. Department of Earth Sciences. Carleton University. Otawa. Ontario.

Recibido: enero 2017

Revisado: julio 2017

Aceptado: enero 2018

Publicado: junio 2019 